\title{
INDIVIDUAL AUTONOMOUS NAVIGATION SYSTEM
}

\author{
StanisŁaW Popowski, Witold Dąbrowski
}

Center of Space Technologies, Avionics Division, Institute of Aviation, 02-256 Warszawa, Al. Krakowska 110/114 stanislaw.popowski@ilot.edu.pl,witold.dabrowski@ilot.edu.pl

\begin{abstract}
The article presents the Individual Autonomous System Navigation (IANS) supporting-rescuer or firemen in terms of navigation. Basic assumptions, which such a system has to fulfill in terms of functionality and accuracy, are presented. The concept of the ISAN system is based on the implementation of inertial navigation system which the only one to permit fully autonomous functioning. Measurement sensors of the navigation system with microprocessor board are placed in the rescuer's shoe. To limit the escalation of the navigation errors value, which in the case of inertial navigation rises exponentially, a procedure of navigation parameters upgrading at every step of the rescuer is introduced to the proposed system. This procedure guarantees the required accuracy of navigation achievement. The article describes a developed and manufactured demonstrator of the technology and presents main results of its research. The research conducted in a building consisted in walking on the same level several hundred meters in less than 10 minutes. A walking test with a change of walking height was also performed in order to estimate the accuracy of the vertical channel. Results of the demonstrator's tests let us conclude that the error of navigation is below $1 \%$ of the travelled distance and the accuracy is linear in respect to time. The achieved accuracy is fully sufficient for a practical IANS application.
\end{abstract}

Keywords: rescuer navigation system, inertial navigation system, ZUPT procedure, Individual Autonomous Navigation System, IANS.

\section{INTRODUCTION}

During rescue operations in tall buildings, underground garages, tunnels, mines, under conditions of dense smoke and various natural disasters it is important, from security point of view, to know the location of the rescuer. The following system is a proposal of navigation support for rescuers. This system is adapted for a single rescuer's use during his/her given task. The proposed solution could be called "personal", but ultimately the name of the Individual Autonomous Navigation System (IANS) was chosen to emphasize its two essential features:

- Established link to a single person (a firefighter, a rescuer)

- Autonomous mode of operation - independent from any external signals (e.g. satellite signals of navigation systems, radio signals, etc.). 
The definition of the latter requires clarification. The requirement that the system should be autonomous does not mean that its concept rejects in advance use of any navigation method based on external signals, such as the GPS satellite navigation system. If such signals are available, nothing will prevent them from being used. However, this requirement implies that there must be a strictly autonomous "kernel" in the system, which will also deal with positioning in the absence of any outside signals. This will be at the expense of navigation accuracy but the system must be able to handle it.

The above manner of defining the object of deliberation imposes some of its features:

- This device must not be large, its mass and dimensions should be small.

- It cannot restrict the movement of a person and cannot be a fragile instrument.

- The power demand of the system must be low, i.e. the device should function properly for many hours without special service interventions, such as recharging batteries or changing batteries.

- It should be easy to use.

The inertial navigation [1] is a natural and essential way of addressing the above-mentioned "strictly autonomous kernel of the system". It consists in determining the current position from the measurements of acceleration and angular velocity of the object the position of which we want to determine. This is achieved by a double integration of acceleration in the navigation system: with the initial conditions and with sensors orientation taken into account. Due to the double integration in such a system errors will appear over time and will grow parabolic. A rapid buildup of errors will make the system unusable in a short time. To solve this problem, the introduction of the Zero Velocity UPdaTes procedure [2] was proposed. This procedure includes updating the parameters of inertial sensors when the object is immobile in relation to the ground. In the case of placing inertial sensors in the rescuer 's shoe, the walk causes the parameters to update at each step (at the shoe contact with the ground). This is a way to radically reduce errors. Errors in this case will grow not parabolically but proportionally to the navigation time. Initially, the accuracy was set at $1 \%$ of the distance travelled.

The problem of locating people's position or movement in conditions that impede orientation is very up-to-date. It has been dealt with by many teams in the world, for example in the article[3] authors have conducted a brief review of methods supporting classic inertial measurement in the ZUPT technique and have shown results of studies using the low cost class MTI -G, AHRS (Attitude Heading Reference System) equipment. The detection of the rest phase of the foot during movement and the possibility of detecting the vertical coordinate is also discussed. In the work [4], the issues of inertial personal navigation are thoroughly described, in particular the methods of limiting the directional error. A number of options for methods of compensation, sensor characteristics and filter integration are given. Article[5] gives an interesting algorithm for step detection and its length so there is no need for double integration of accelerations. The results of the experiment are presented. The work [6] discusses the integration of ZUPT and ZARU (Zero Angular Rate Update) systems in individual navigation applications. In the work [7] a careful analysis of the phase of human lower limb movement has been carried out in the aspect of motion phase detection used in the ZUPT algorithms. In the paper [8] an interesting concept of placing inertial sensors is presented, not "traditionally" attached to footwear, but in the belt of a moving man. Such a placement of sensors 
makes it necessary to develop a specific method of rest phase detection (for ZUPT). The work [9] presents a developmental navigation system based mainly on GPS and methods of calculating inertial fixes based on GPS. In the paper [10], the phenomenon of PLUPT for use in the analyzed navigation and the limitations and dangers of using the PLUP are presented.

\section{THE CONCEPT OF A NAVIGATION SYSTEM}

Inertial navigation is one of the types of dead reckoning. Given the start point, measuring the direction of movement at any moment and the distance travelled related to the assumed coordinate system, you can calculate the current position (Fig. $1 \div 3$ ). In inertial navigation the components of the acceleration in the inertial system are measured and the velocity is the intermediate. Acceleration components are determined by accelerometers which generally work by measuring the inertial force of the evaluated mass held in a fixed position by means of suspension forces.

Unfortunately, measurements using linear accelerometers do not take into account angular displacements and each angular movement of the sensors causes an error. An additional device is needed to adequately align the platform with respect to the assumed coordinate system. Such a device may be a gyroscope capable of measuring angular displacements in the inertial space (Fig. 1 and 2).

The problem of navigating mobile objects such as individual rescuer is to navigate in relation to the rotating Earth rather than the inertial space. In addition, there is one more problem associated with maintaining the accuracy of inertial navigation in time. It occurs when the accelerometer, with its axis of measurement in line with the direction of object's motion (omitting all the other errors), measures acceleration with accuracy $\delta f$, then after time $t$ due to double integration the positioning error will be:

$$
\Delta x_{p}=\frac{\delta f \cdot t^{2}}{2}
$$

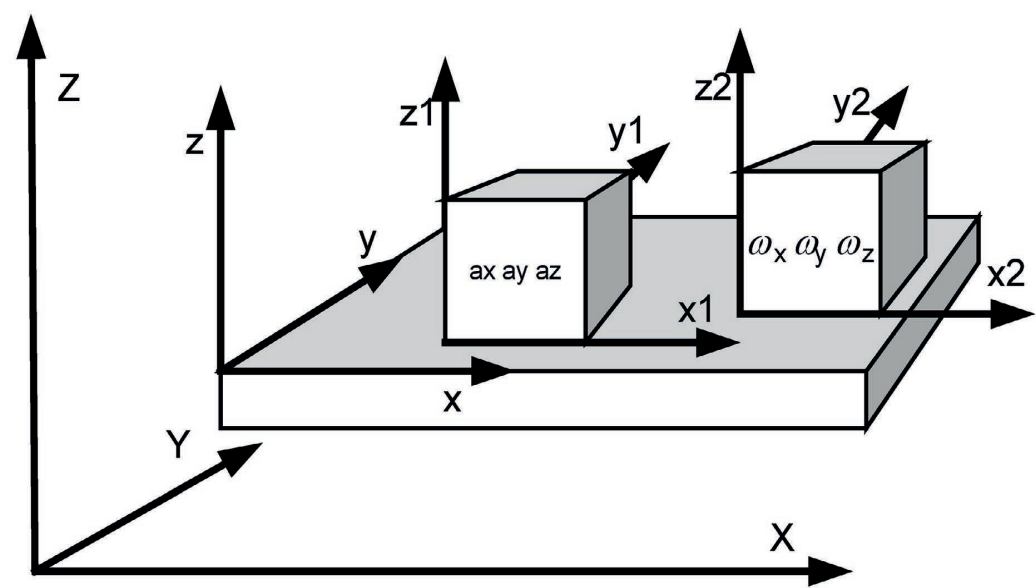

Fig. 1. Inertial Navigation:- platform with sensors. XYZ - navigation system, xyz - sensor-related system [2] 
Similarly, the gyroscope drift $\delta \omega$ causes a tilt error from the nominal horizontal plane and also causes position errors equal to:

$$
\Delta x_{g}=\frac{g \delta \omega \cdot t^{3}}{6} \text {. }
$$

If we have gyroscopes with an accuracy of $10 \mathrm{deg} / \mathrm{h}$ and accelerometers with an accuracy of $0.001 \mathrm{~g}$, then within $600 \mathrm{~s}$ (10 min.) the inertial navigation system will reach a position error of approximately $19250 \mathrm{~m}$. Such accuracy of navigation is unacceptable. In order to limit error values to acceptable levels, the ZUPT procedure was introduced.

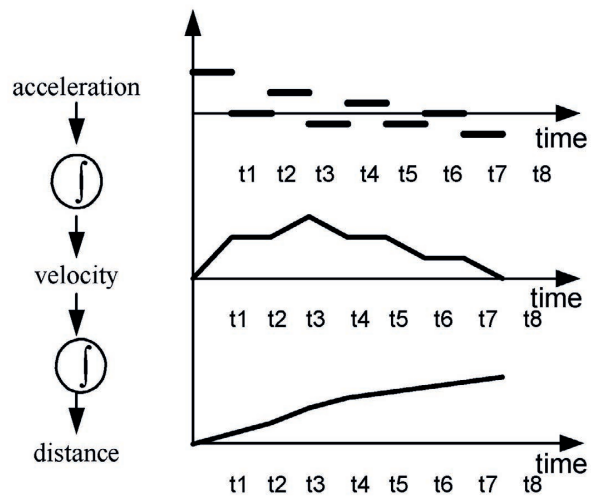

Fig. 2. The process of double integration of acceleration [2]

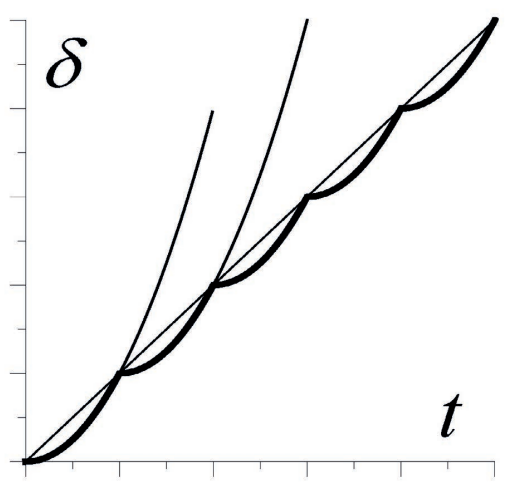

Fig. 3. Sample operation of the ZUPT procedure[2], $\delta$ - location error, $t$ - time of navigation process [2]

After introducing the ZUPT procedure (Fig. 3) with an assumption that a single step takes $0.5 \mathrm{~s}$ (after each step the procedure is repeated) and the distance travelled during $600 \mathrm{~s}$ is $600 \mathrm{~m}$ the total theoretical error from the analyzed sensors will be less than $1 \mathrm{~m}$.

Figure 4 shows a flowchart of the system. According to the ZUPT procedure, the calculation algorithm consists of two branches. One applies to navigating, and the second to the rest phase. There is a third, very important element of the system, the verification of the criteria to carry out the ZUPT procedure.

There is a set of sensors marked on the left side of the diagram. Accelerometers (a), gyroscopes $(\mathrm{w})$, magnetometers $(\mathrm{m})$, pressure sensor (Un) and static pressure sensor (ps). When the system is switched on, the initial angles of orientation, pitch angle and roll angle are determined basing on the gravitational acceleration. With these angles the transformation matrix is calculated, used to reduce the magnetic field measurements to the horizontal plane and then to calculate the magnetic course. In the considered autonomous system (for work in buildings) the magnetic course is introduced only as an initial condition. It is about connecting to the directions of the walls and baffles of the building. Optionally, you can enter a "zero" startup, assuming we start navigation from northern side or enter a real value determined by other techniques.

In order to calculate the distance vector components in an earth system, it is necessary to calculate 


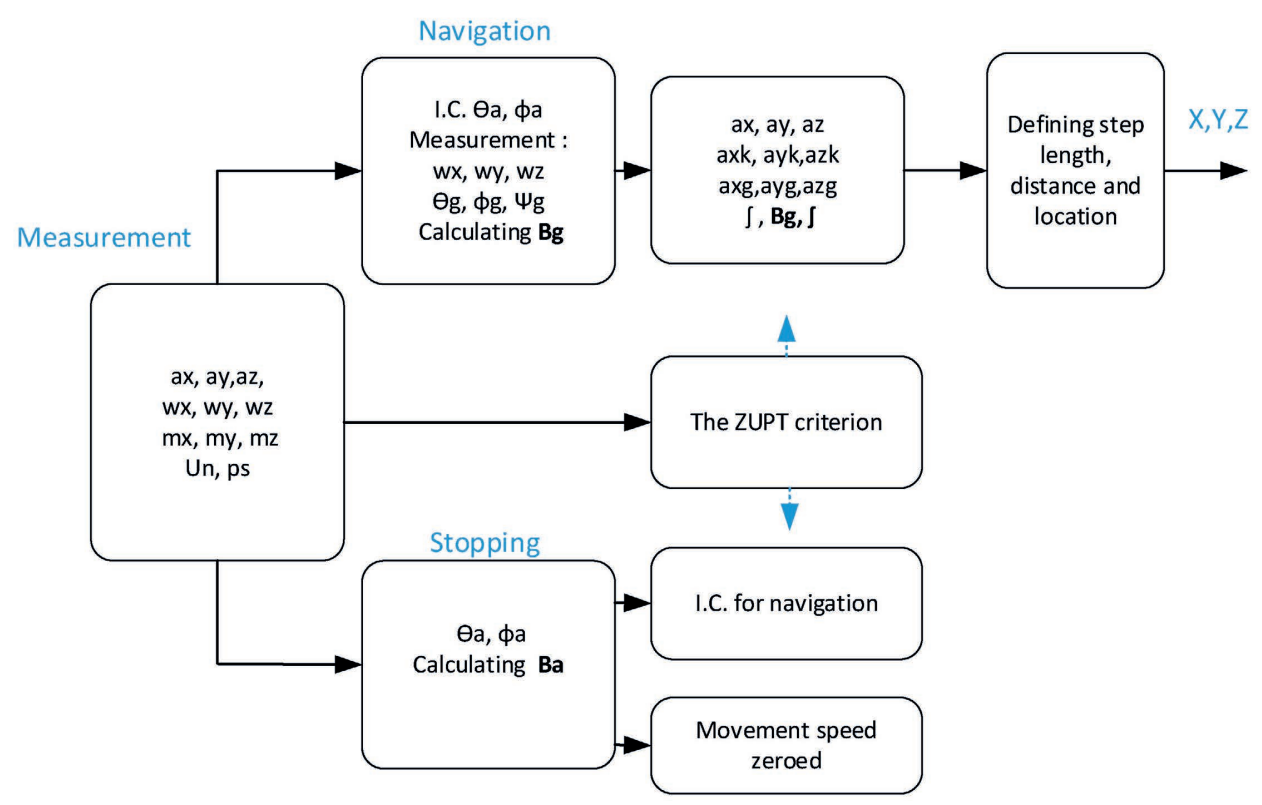

Fig. 4. The general scheme of IANS system [Popowski, Dąbrowski, 2016]

the acceleration components measured in the object system, taking into account the acceleration resulting from the curvilinear movement. After the transformation to the normal earth system, and subtraction of earth gravity we calculate (by first integration) the velocity components in the earth system and then integrate them again (formulas (3) - (8) and Fig. 5). The acceleration resulting from the motion of the object can be written as:

$$
\left[\begin{array}{c}
a_{x}^{n} \\
a_{y}^{n} \\
a_{z}^{n}
\end{array}\right]=\left[\begin{array}{c}
\dot{u} \\
\dot{v} \\
\dot{w}
\end{array}\right]+\left[\begin{array}{c}
q w-r v \\
r u-p w \\
p v-q u
\end{array}\right]
$$

where: $\quad a_{x}^{n}, a_{y}^{n}, a_{z}^{n}$ - acceleration due to linear and curvilinear motion, $u, v, w$ - linear velocities in the object system, $p, q, r$ - angular velocity in the object system.

Values $\dot{u}, \dot{v}, \dot{w}$ are linear accelerations along the $\mathrm{x}, \mathrm{y}$ and $\mathrm{z}$ axes. The second component of the sum is the acceleration of curvilinear motion with corresponding linear and angular velocities.

In addition to the components specified by the values (3), gravitational acceleration must also be taken into account. For Warsaw it is $g=9.81241 \mathrm{~m} / \mathrm{s}^{2}$. Since the expression (3) is written in the object's system therefore, the acceleration due to the local vertical direction must be reduced to the same system. To do this, it is necessary to use the Euler transformation matrix [E] applying orientation angles obtained from the orientation system. 


$$
E=\left[\begin{array}{llc}
\cos \Psi \cos \Theta & \sin \Psi \cos \Theta & -\sin \Theta \\
(\cos \Psi \sin \Theta \sin \Phi-\sin \Psi \cos \Phi) & (\sin \Psi \sin \Theta \sin \Phi-\cos \Psi \cos \Phi) & \cos \Theta \sin \Phi \\
(\cos \Psi \sin \Theta \cos \Phi+\sin \Psi \sin \Phi) & (\sin \Psi \sin \Theta \cos \Phi-\cos \Psi \sin \Phi) & \cos \Theta \cos \Phi
\end{array}\right]
$$

where: $\Theta$ - pitch angle,

$\Phi$ - roll angle,

$\Psi$ - yaw angle.

The gravitational acceleration in the object system will be:

$\left[\begin{array}{c}a_{x}^{g} \\ a_{y}^{g} \\ a_{z}^{g}\end{array}\right]=\left[E\left[\begin{array}{c}0 \\ 0 \\ -g\end{array}\right]=\left[\begin{array}{c}g \sin \Theta \\ -g \cos \Theta \sin \Phi \\ -g \cos \Theta \cos \Phi\end{array}\right]\right.$

Considering (3) and (5), the acceleration measured on the object can be written as:

$$
\left[\begin{array}{l}
a_{x} \\
a_{y} \\
a_{z}
\end{array}\right]=\left[\begin{array}{l}
a_{x}^{n} \\
a_{y}^{n} \\
a_{z}^{n}
\end{array}\right]+\left[\begin{array}{l}
a_{x}^{g} \\
a_{y}^{g} \\
a_{z}^{g}
\end{array}\right]=\left[\begin{array}{c}
\dot{u}+q w-r v \\
\dot{v}+r u-p w \\
\dot{w}+p v-q u
\end{array}\right]+\left[\begin{array}{c}
g \sin \Theta \\
-g \cos \Theta \sin \Phi \\
-g \cos \Theta \cos \Phi
\end{array}\right]
$$

From here you can determine the linear acceleration of an object in the object system:

$$
\left[\begin{array}{c}
\dot{u} \\
\dot{v} \\
\dot{w}
\end{array}\right]=\left[\begin{array}{l}
a_{x} \\
a_{y} \\
a_{z}
\end{array}\right]-\left[\begin{array}{c}
q w-r v \\
r u-p w \\
p v-q u
\end{array}\right]-\left[\begin{array}{c}
g \sin \Theta \\
-g \cos \Theta \sin \Phi \\
-g \cos \Theta \cos \Phi
\end{array}\right]
$$

And then transpose them into the earth system.

$$
\left[\begin{array}{c}
\dot{V}_{x} \\
\dot{V}_{y} \\
\dot{V}_{z}
\end{array}\right]=[E]^{T}\left[\begin{array}{c}
\dot{u} \\
\dot{v} \\
\dot{w}
\end{array}\right]
$$

where: $\dot{V}_{x}, \dot{V}_{y}, \dot{V}_{z}-$ velocity component in navigation system.

In order to obtain the components of displacement it is necessary to integrate the components of velocity in the earth system again. The entire calculation process is shown in Figure 5.

When calculating the acceleration of linear motion in the navigation system, the non-essential components are neglected, their value being below the sensitivity threshold of the sensors used, e.g. relative and Coriolis accelerations. This whole procedure is performed during navigation. The movement phase (hold - navigation) is triggered by the result of checking the fulfillment of feasibility criteria of the ZUPT procedure. The criterion distinguishes the rest state and navigation 
state. We use a pressure sensor located in the shoe, under the heel to calculate the rest criterion. When the foot is placed on the ground, the pressure sensor is loaded, and when the foot is raised, the sensor is unloaded. These variable pressures generate control signals that determine the value of the ZUPT indicator. In addition to the pressure sensor, angular velocity or acceleration measurements can also be used to calculate the rest criterion.

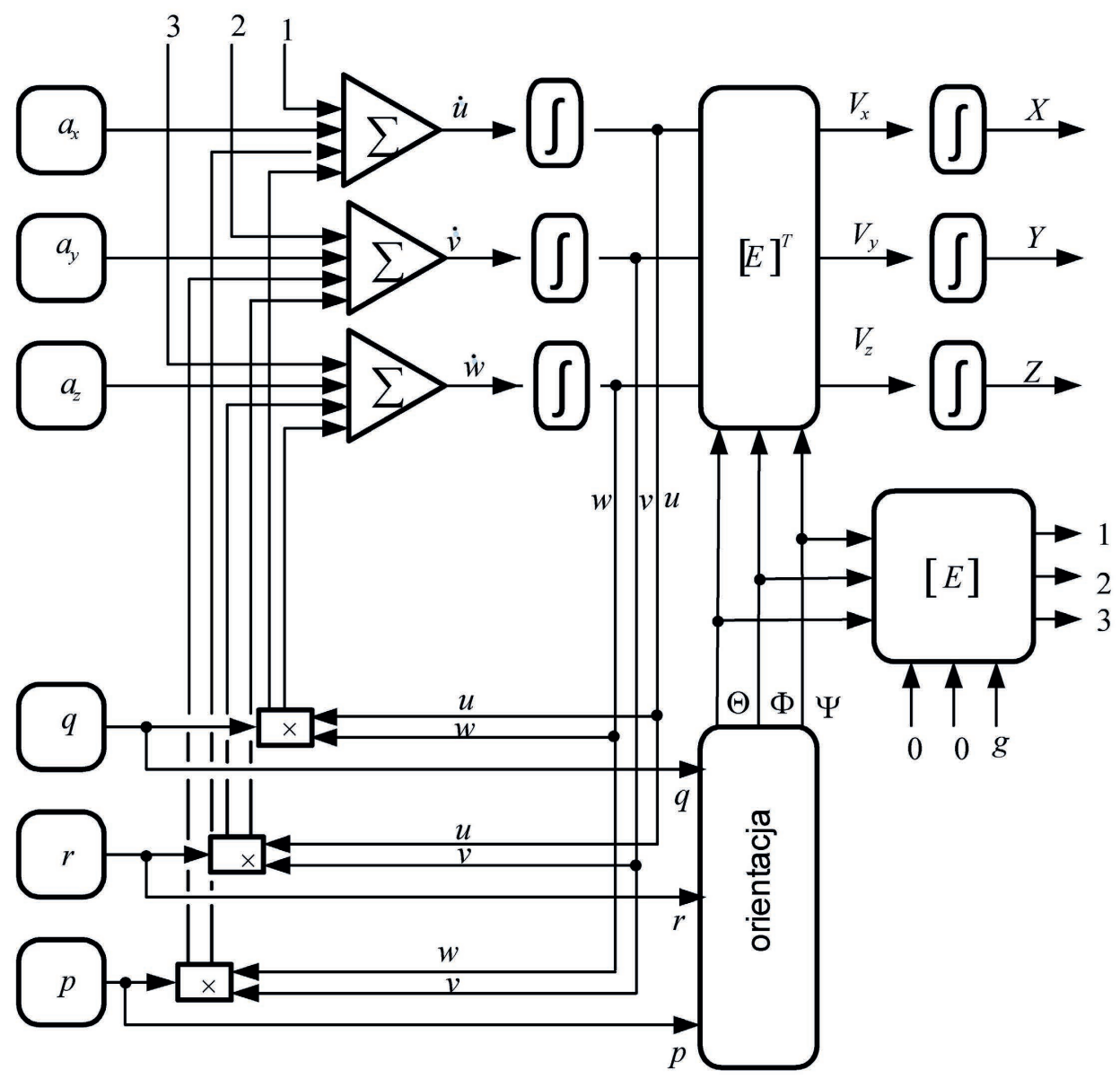

Fig. 5. Diagram of navigational calculations [1]

When the system detects the stop state (the shoe has been loaded), the navigation process is aborted. The navigation result is sent to the CAN bus. In this state, the pitch and roll angles of the accelerometers are measured and introduced as initial conditions for the spatial orientation measurement system. At the same time, the linear velocity (the result of the first integration) will be zeroed. We do not enter new values in the course channel. As the starting condition for the course in the new step we enter the final value of the course from the previous step. Thus the value of the course depends only on the initial condition and the accuracy of gyroscopes. This is an option designed for high-noise 
situations. When navigating in a magnetic field noise free environment, but without access to the GPS signal (work outside buildings with disturbed GPS signals), it is possible to correct the gyroscopic course with a magnetic course in a complementary filtration process [1], [14].

\section{IMPLEMENTATION OF THE TECHNOLOGY DEMONSTRATOR}

In the implemented technology demonstrator has been used:

- inertial measuring modules type ADIS 16448,

- microprocessor-based converter STM32F407VG produced by ST Microelectronics [15], [16],

- resistive pressure sensor CP6 produced by IEE.
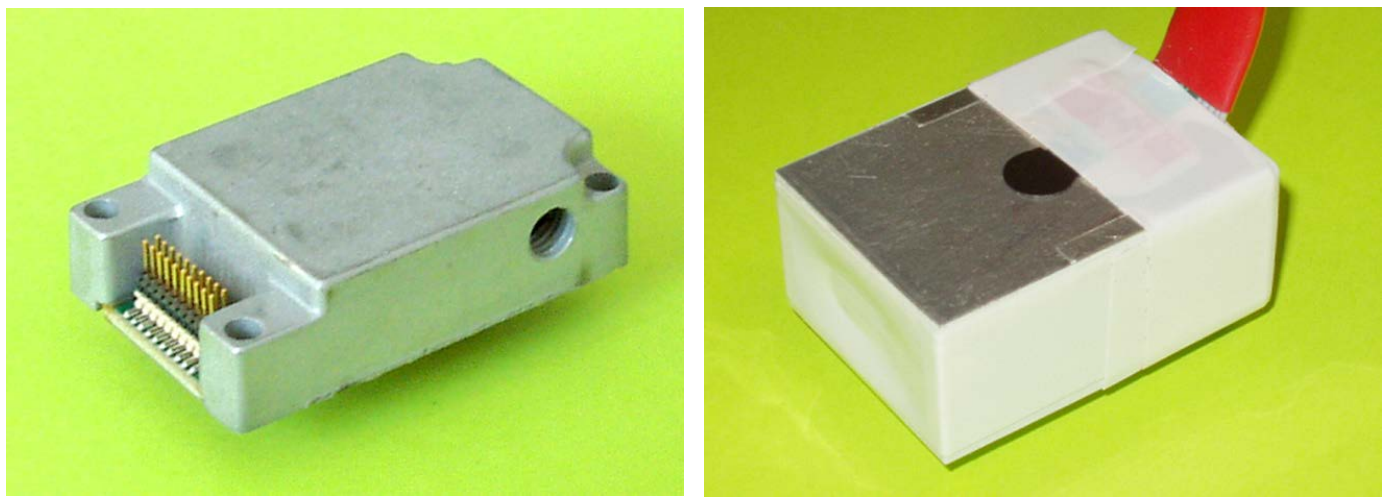

Fig. 6. ADIS 16448 module (left), casing of sensor assembly (right) [Popowski, Dąbrowski, 2016]
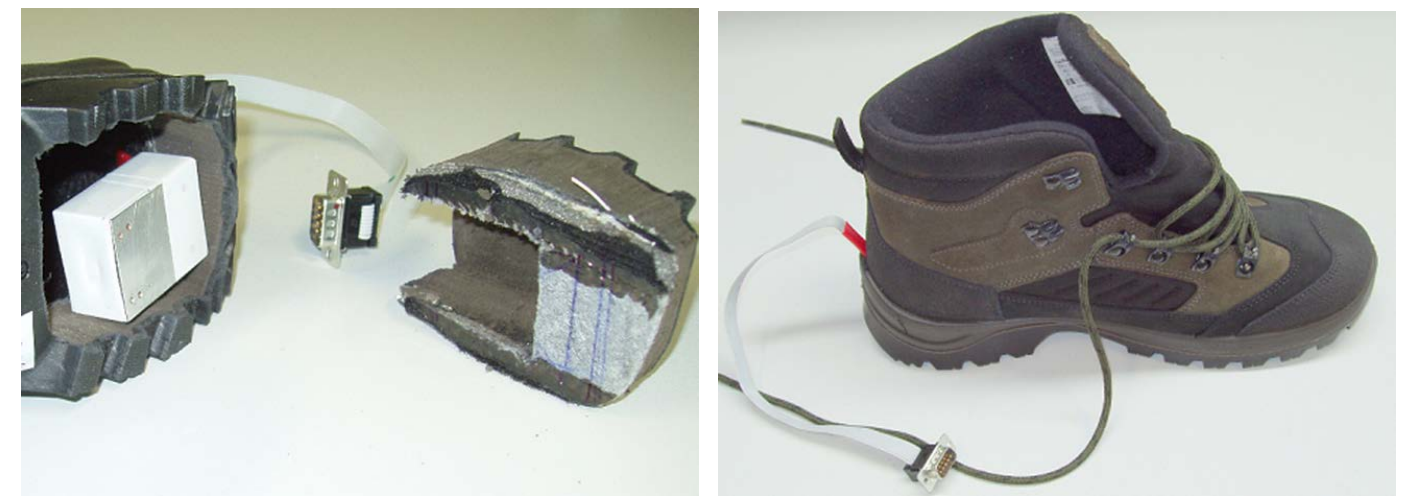

Fig. 7. 16448 module during assembly in the shoe (left) and finished shoe assembly (right) [Popowski, Dąbrowski, 2016]

First, a functional model of the navigation system was made. For this model, a set of sensors was used in one of the shoes. Figure 6 shows the view of the module used and the module assembly in the case with the pressure sensor attached. Figure 7 shows how the sensors are built into the shoe, and in Figure 8 the view of the complete model of the system ready for testing. 


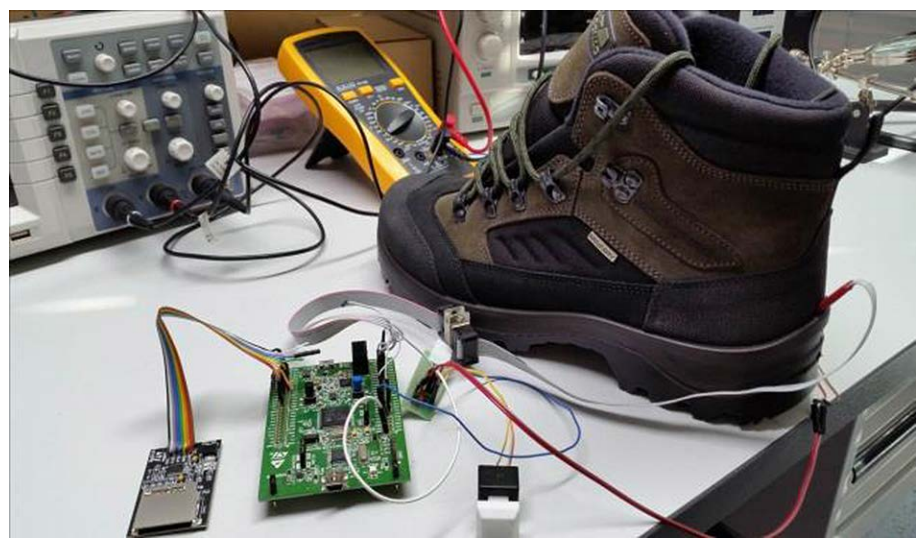

Fig. 8. Measurement system during laboratory tests (left) and ready for testing (right) [Popowski, Dąbrowski, 2016]

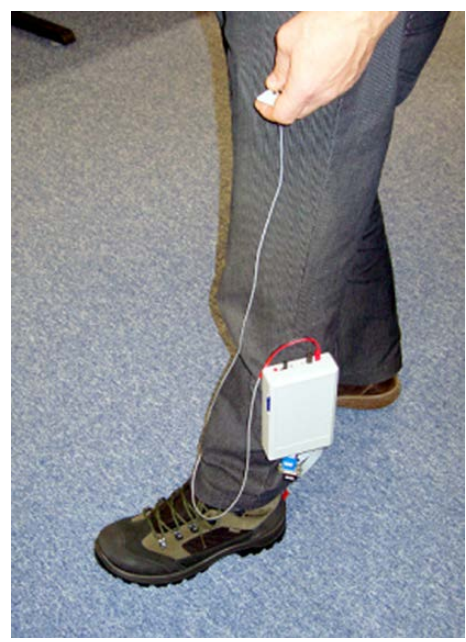

\section{TESTS CONDUCTED ON THE TECHNOLOGY DEMONSTRATOR}

The demonstrator's study consisted of three parts. The first part of the study consisted of registering all measured values through a simple transition from point A to point B in a straight line. These values were then used to calculate characteristic parameters of the navigation system: orientation angles, gravitational acceleration, curvilinear acceleration, etc. They were also used to find, by means of simulation tests, a suitable criterion for the ZUPT procedure. The second part of the research consisted of checking the functionality of the navigation system after programming the system converter, with previously verified algorithm and the accepted criterion of the ZUPT procedure. During these activities, the theoretical accuracy of the system obtained under the conditions of the flat route was confirmed experimentally (Figure 9). The third group of tests consisted of checking the operation of the navigation system in the vertical channel. In this case, the effectiveness of introducing height correction from static pressure using complementary filtration was checked.

\subsection{Preliminary study of the system}

The study was carried out on the building floor traced track including waypoints. The waypoints were placed in the corridor of the building (red points numbered 1 to 6 - Fig. 9) at the geometrical locations of the vertices of the two squares whose side is $8 \mathrm{~m}$. Measurements and registrations were made during the transition between selected points. The simplest transition consisted of starting from point 1 , passing $16 \mathrm{~m}$ to point 3 , turning back and returning to point 1 . In sample illustrations from recorded motion parameters they were presented for this exercise (Fig. 10). 


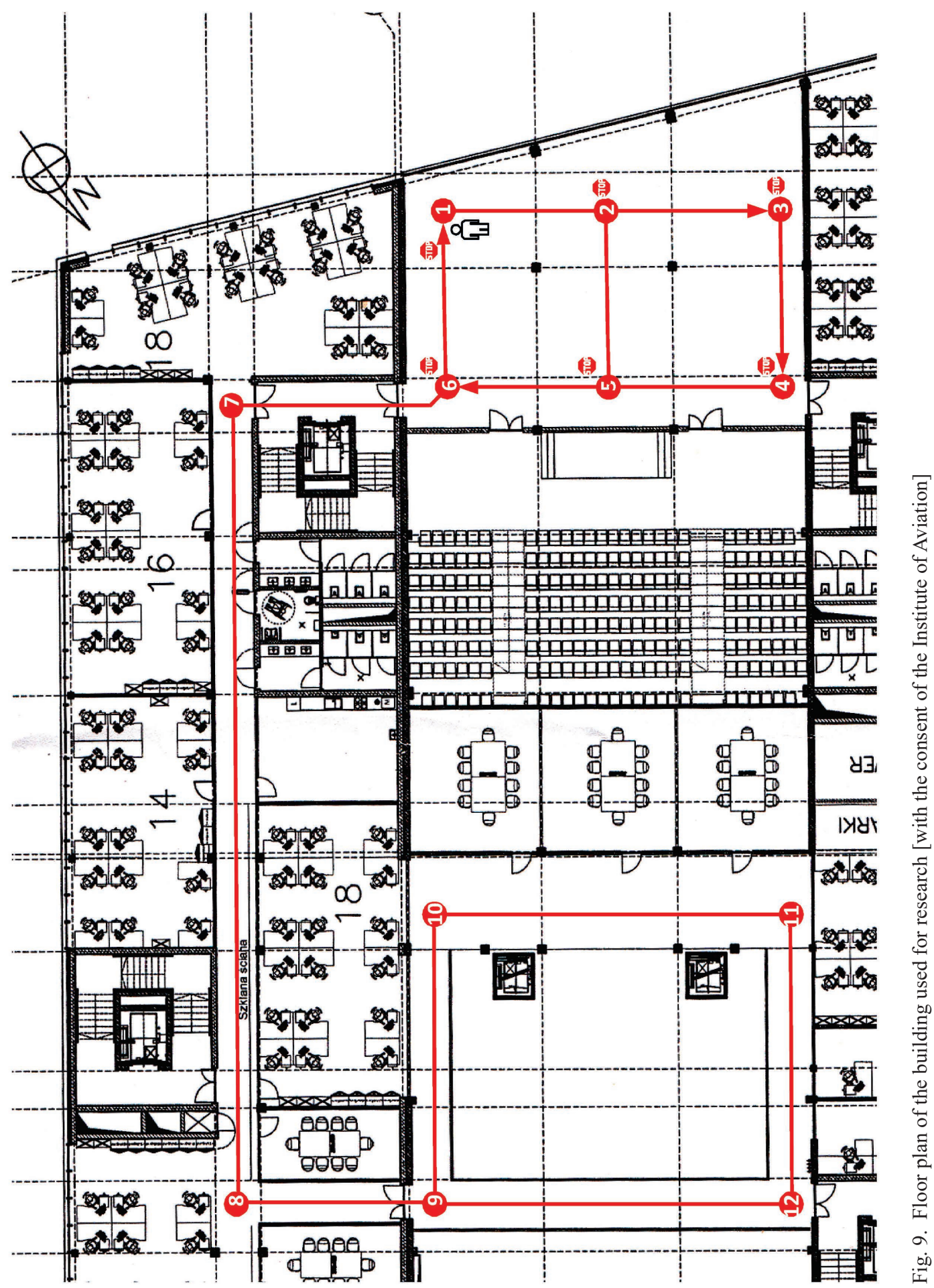


Below there are recorded motion parameters for the simplest exercise of transitioning from point 1 to point 3 and returning to point 1 . Figure 10 shows the recorded acceleration (a) in $g$ units measured in the shoe system. The $\mathrm{x}$ axis was facing the front of the shoe, the $\mathrm{y}$ axis to the right and the $\mathrm{z}$ axis down.
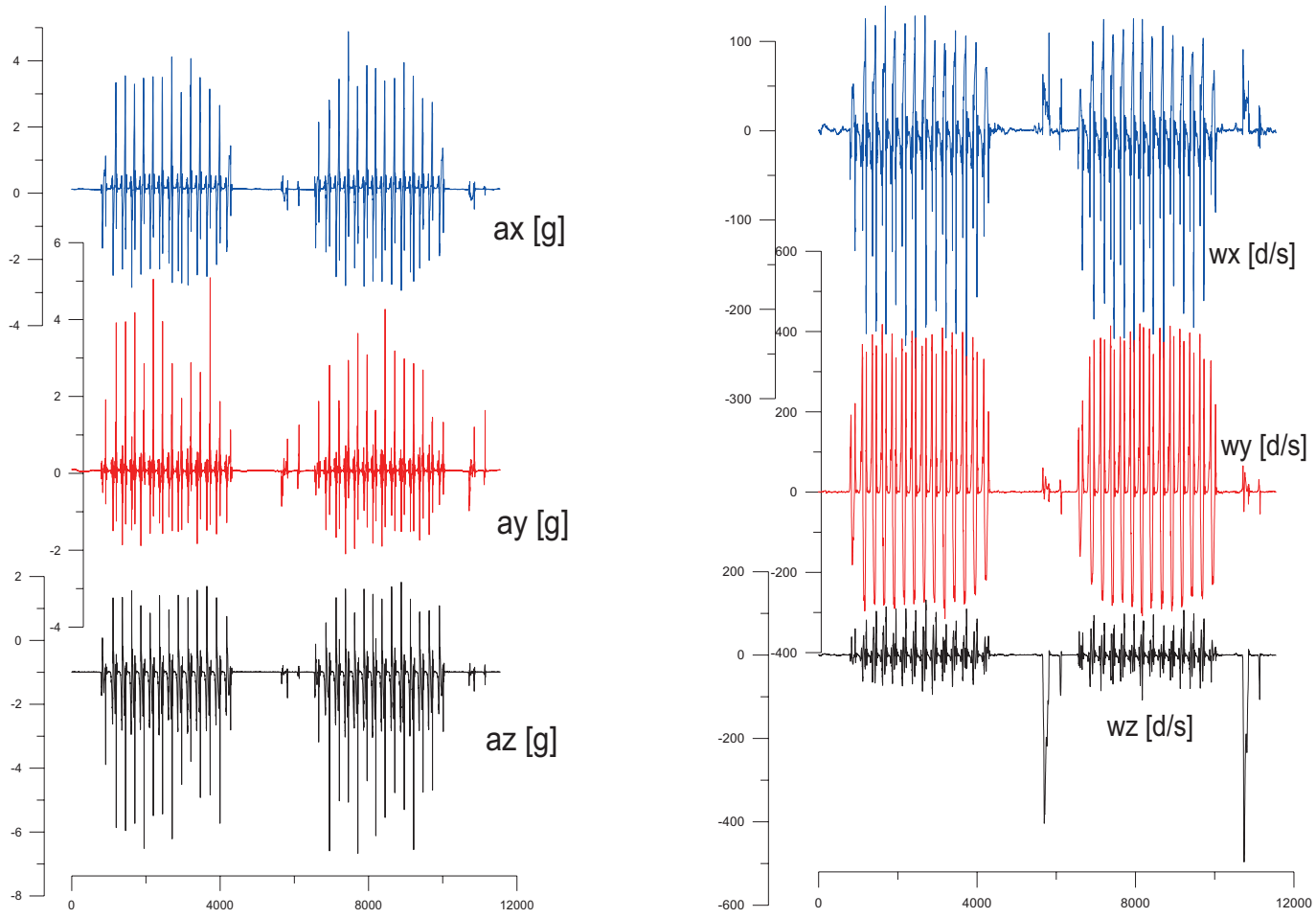

Fig. 10. Acceleration component graph (left) and angular velocity (right) as a function of next sample [Popowski, Dąbrowski, 2016]

Figure 10 (right) also shows three angular velocity components (w) measured at the same time in degrees per second. Fig. 11 (left) magnetic field components $(\mathrm{m})$ in miligaus, and Fig. 11 (right) additionally measured parameters: sensor temperature $(\mathrm{t})$ in degrees Celsius, static pressure $(\mathrm{p})$ in hectopascal and force of pressure of the heel (V) presented in volts measured during the test. The above parameters graphs are just examples. The entire set of tests and parameter recordings for various transitions were made.

\subsection{System tests while navigating in a horizontal plane}

Preliminary tests were made using a route determined by 12 waypoints located in characteristic locations of the second floor of Building $X$ at the Institute of Aviation (Fig. 9). The typical, most frequent route led through points 3-2-5-6-7-8-9-10-11-12-9-8-7-6-5-2-3. This route is about $230 \mathrm{~m}$ 
long and the time to complete it while stopping at selected points is about $300 \mathrm{~s}$ ( $5 \mathrm{~min}$.). Point 3 was chosen as a starting point because of the relatively small magnetic field interference there. Thus a magnetic course could be introduced at this point as an initial course.
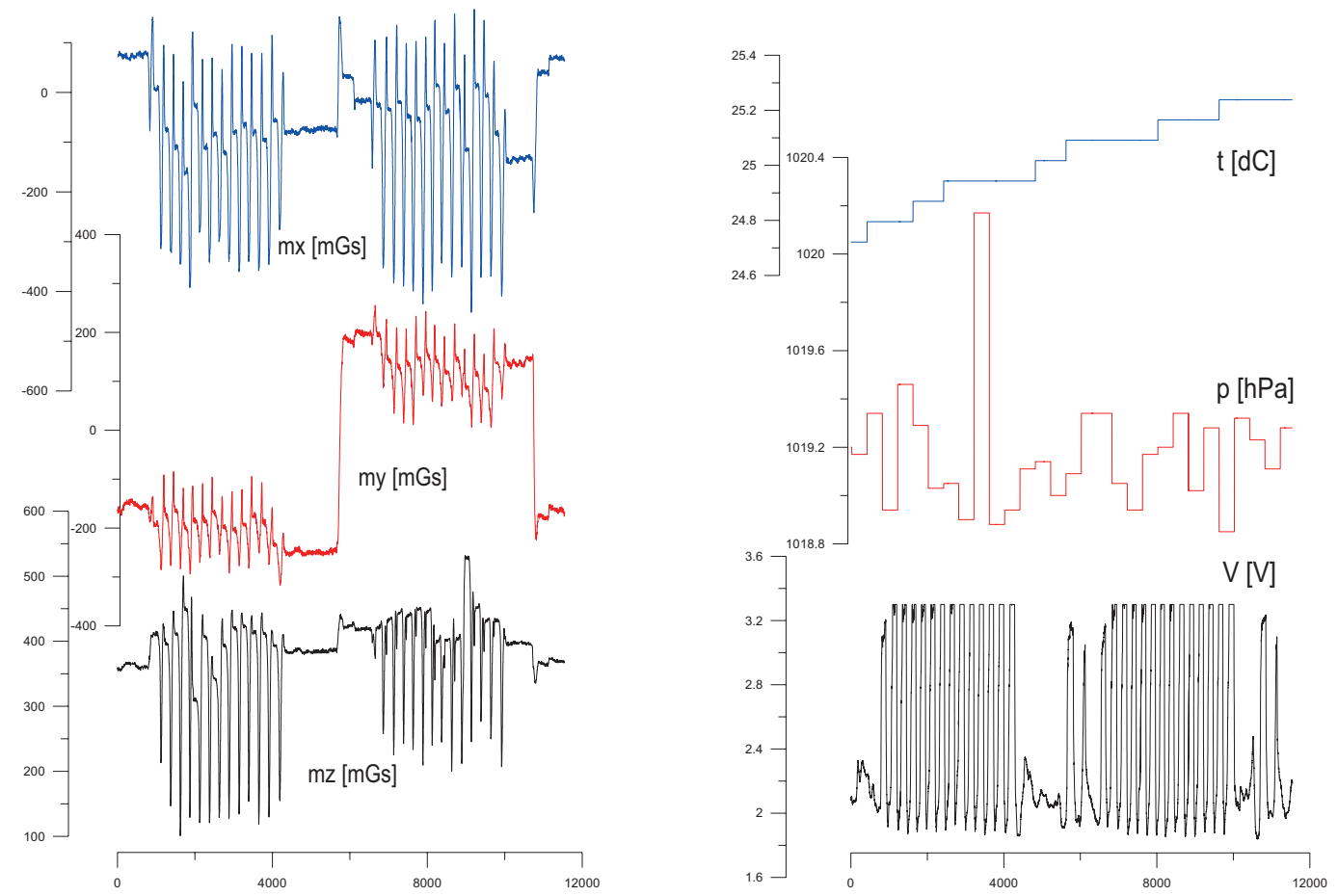

Fig. 11. Graphs of magnetic field components (left) also temperature, pressure and force (right) as a function of the next sample [Popowski, Dąbrowski, 2016]

At first, a simple 3-2-5-4-3 square-track exercise was performed. The result of this test in form of-road trajectory course in the horizontal plane in the N-E coordinate system in meters (relative to the starting point) and other indirect results of calculations of this test are shown in Figures $12 \div 20$.

Fig. 12 (left) shows the course of pitch angle $\Theta$ (in degrees) as a function of time (the number of recorded sample). This is the angle obtained from gyroscopic measurements corrected at the time of fulfilling the condition of the ZUPT from gravitational acceleration measurements. Fig. 12 (right) shows a similarly measured roll angle $\Phi$ in degrees.

Fig. 13 (left) presents a graph with angle $\Psi_{\mathrm{g}}$ course (in degrees) during the entire experiment as a function of time - the number of the recorded sample. This is a gyroscopic course with an initial value determined by the magnetic measurement of the starting point. Fig. 13 (right) shows the course of the ZUPT indicator (wsk1) as a function of time (the number of recorded sample). The value of " 0 " is assigned to the shoe contact with the ground surface when the initial conditions are introduced and the linear speed is reset. A value of " 40 " is entered when the shoe is not in contact with the ground, when navigating. 

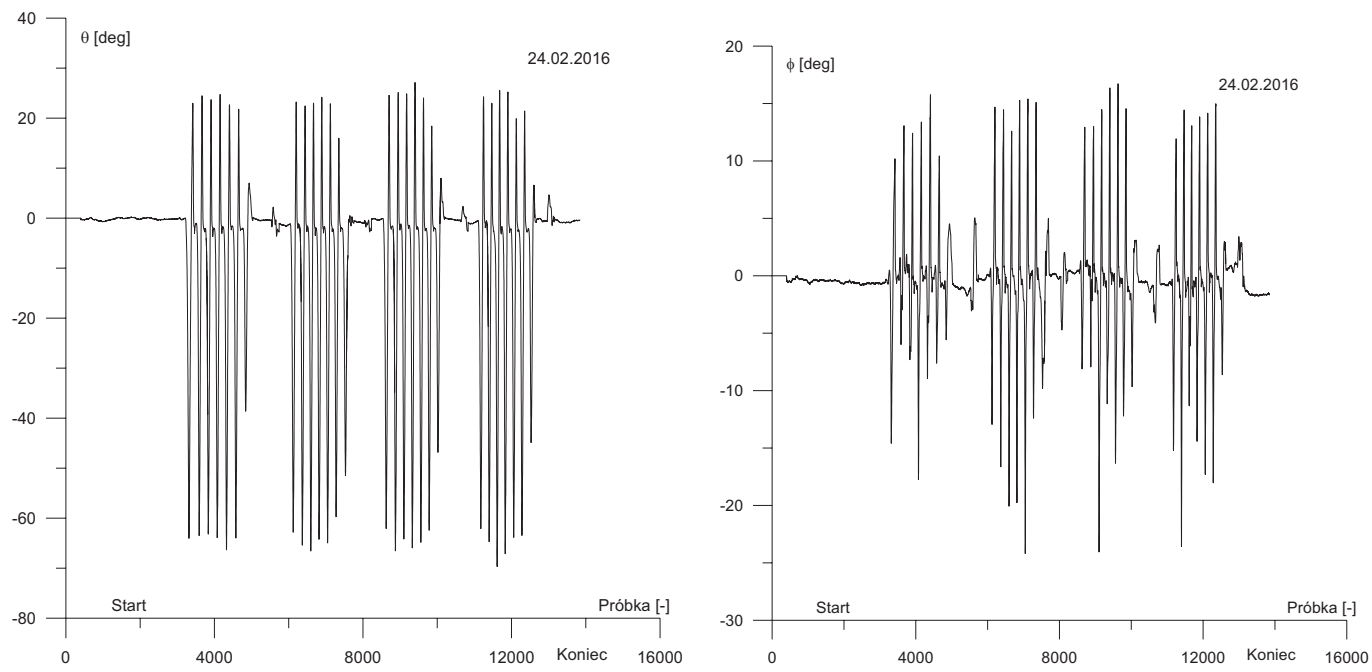

Fig. 12. Pitch angle (left) and roll angle (right) during the march on a square track [Popowski, Dąbrowski, 2016]
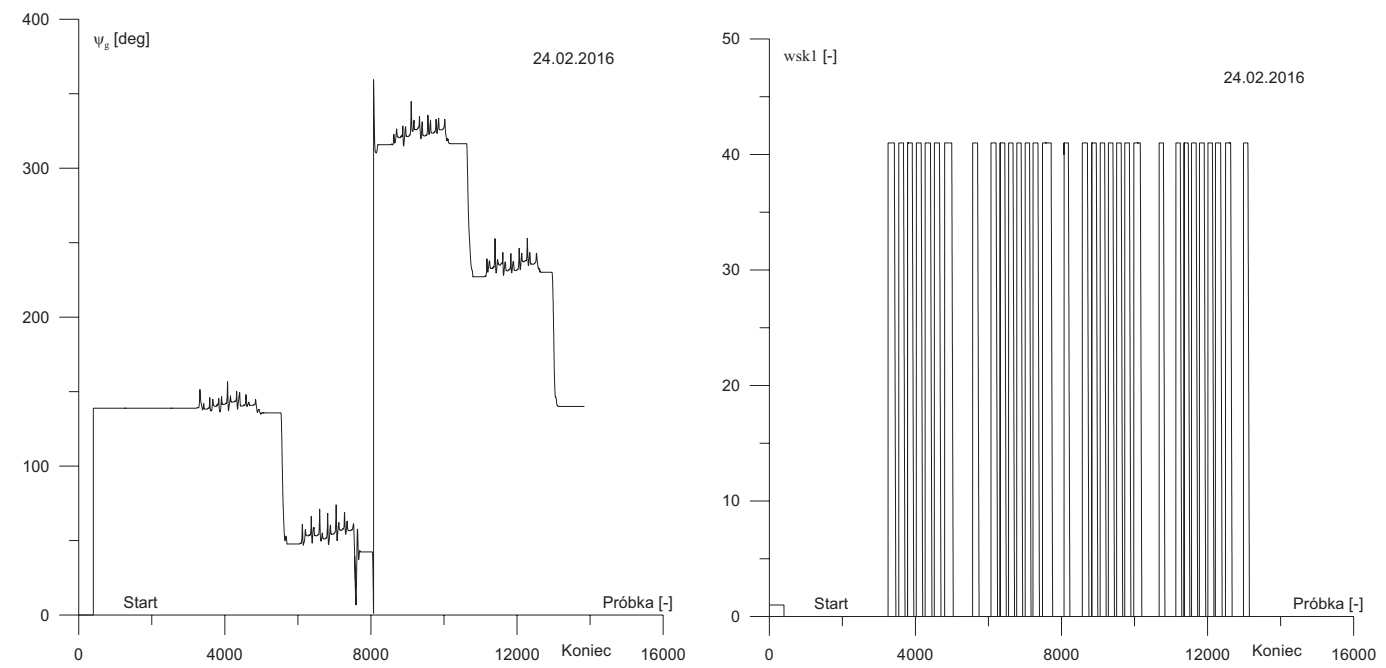

Fig. 13. Pitch angle (left) and ZUPT criterion indicator (right) during the march on a square track [Popowski, Dąbrowski, 2016]

Fig. 14 (left) shows the acceleration pattern we_ $a_{\mathrm{x}}$ (in $\mathrm{m} / \mathrm{s}^{2}$ ) measured by the accelerometer in shoe $\mathrm{x}$-axis of the as a function of time - the number of recorded sample, and in Fig.14 (right) for the same axis gravitational acceleration course.

Figure 15 (left) shows the plot of acceleration value in the curvilinear motion for the same $\mathrm{x}$-axis, and in Figure 15 (right) shoe linear velocity in shoe x-axis after integrating the linear acceleration calculated in (7) as a function of time (number of recorded sample). Fig. 16 shows 

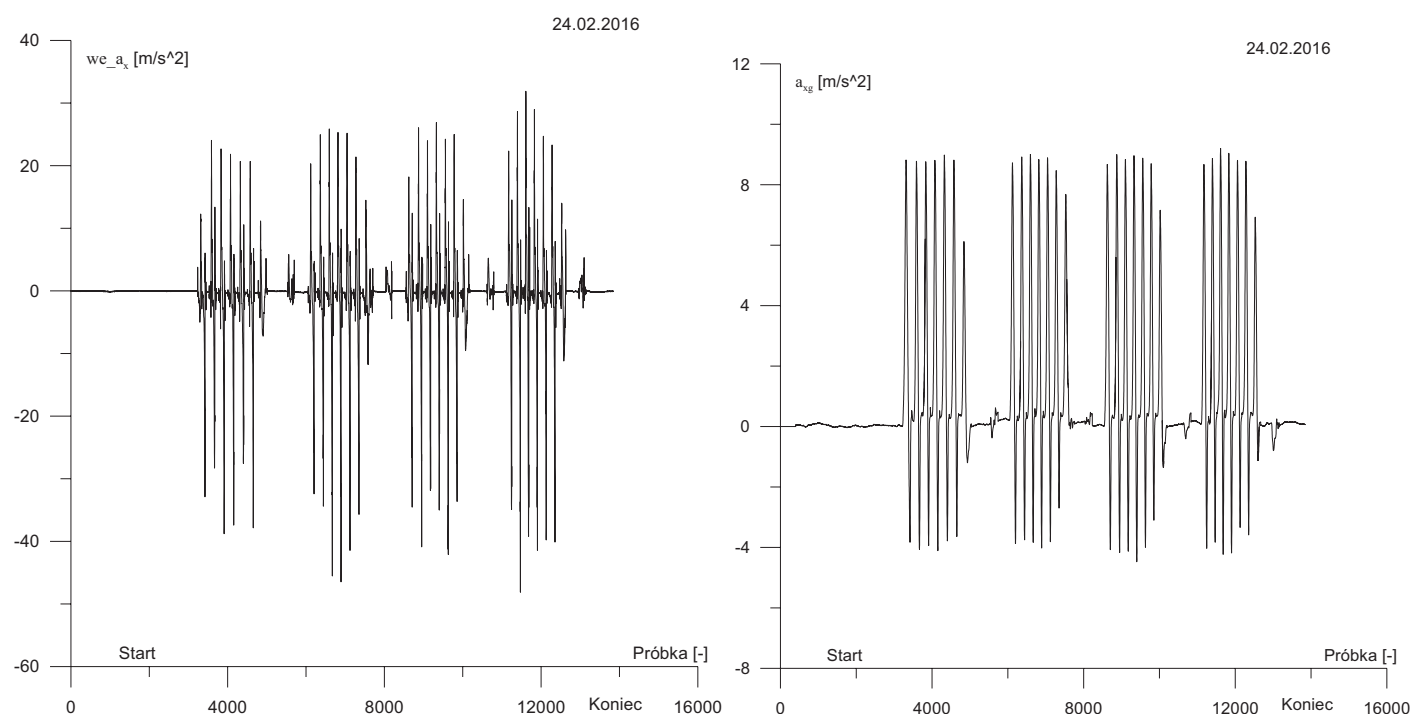

Fig. 14. Acceleration measured in the $\mathrm{x}$ axis (on the left gravitional acceleration in the $\mathrm{x}$ axis (right) during the march on a square track [Popowski, Dąbrowski, 2016]
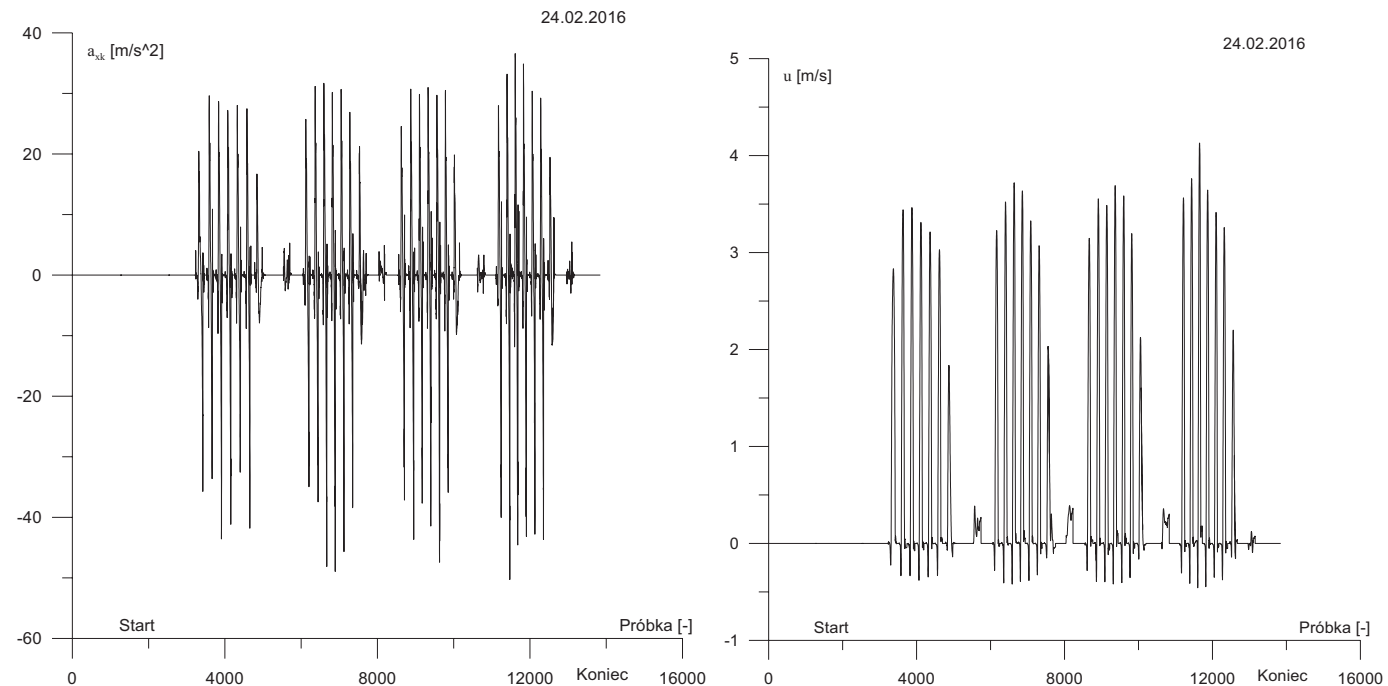

Fig. 15. Acceleration of the curvilinear motion in the $\mathrm{x}$ axis (on the left linear velocity in the $\mathrm{x}$ axis (right) during the march on a square track [Popowski, Dąbrowski, 2016]

the other components of linear velocity in shoe-related system, the $y$ and $z$ axis. Fig. 17 shows the components of the shoe linear velocity after transformation to the earth navigation system (E-N). Fig. 18 shows the course of a change of position, on the left, direction east, and on the right, north. 

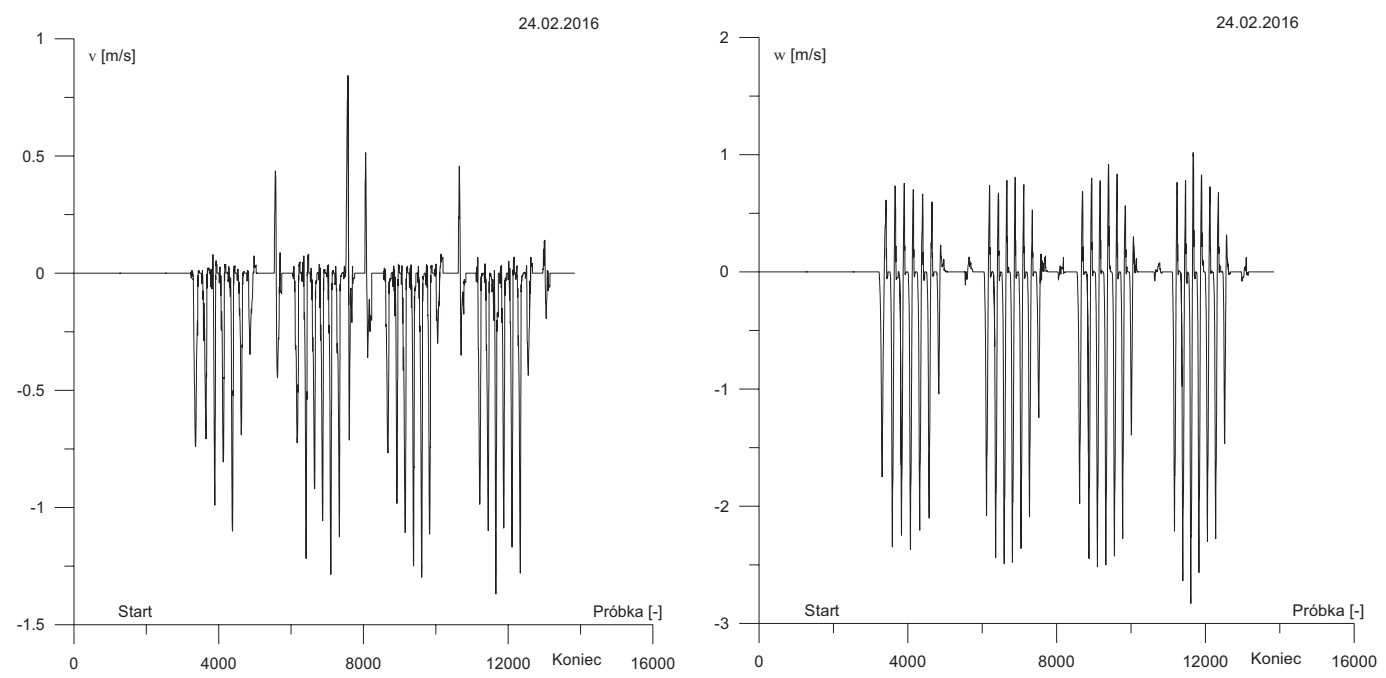

Fig. 16. Linear velocity on the $y$ axis (left) and linear velocity on the $\mathrm{z}$ axis (right) during the march on a square track [Popowski, Dąbrowski, 2016]
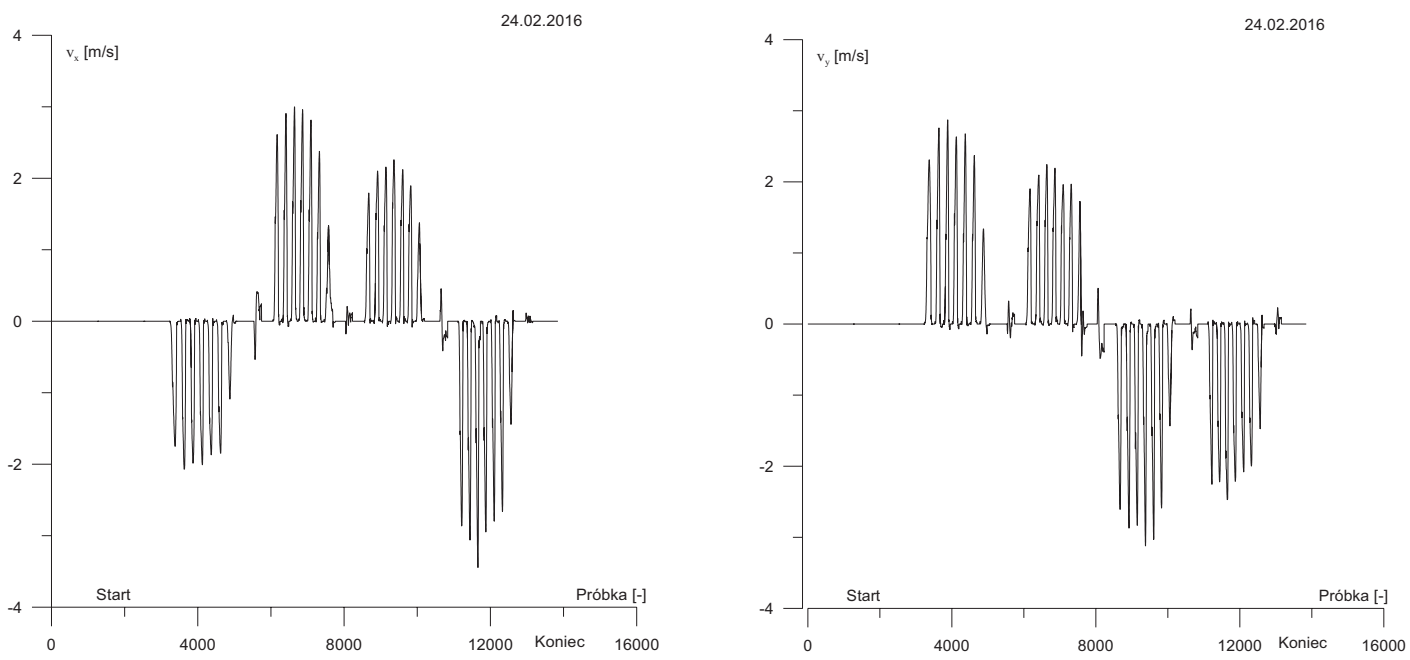

Fig. 17. Components of horizontal linear velocities in the earth related system [Popowski, Dąbrowski, 2016]

The transition path is shown in Fig. 19. A regular square with a side length of $8 \mathrm{~m}$ can be seen. In Fig. 19 on the right, altitude change during this test is displayed. It is about $25 \mathrm{~cm}$. This is the value of error that occurred during the experiment, as a result of lack of correction in the vertical channel. 

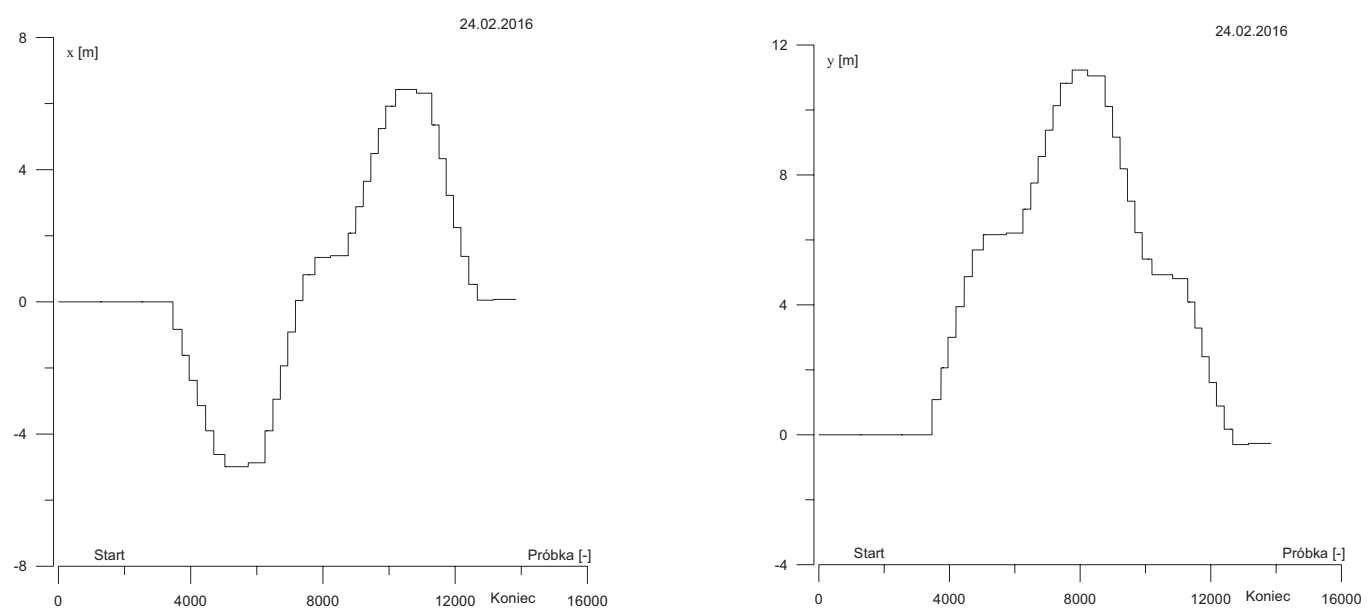

Fig. 18. Components of the horizontal position in earth related system [Popowski, Dąbrowski, 2016]
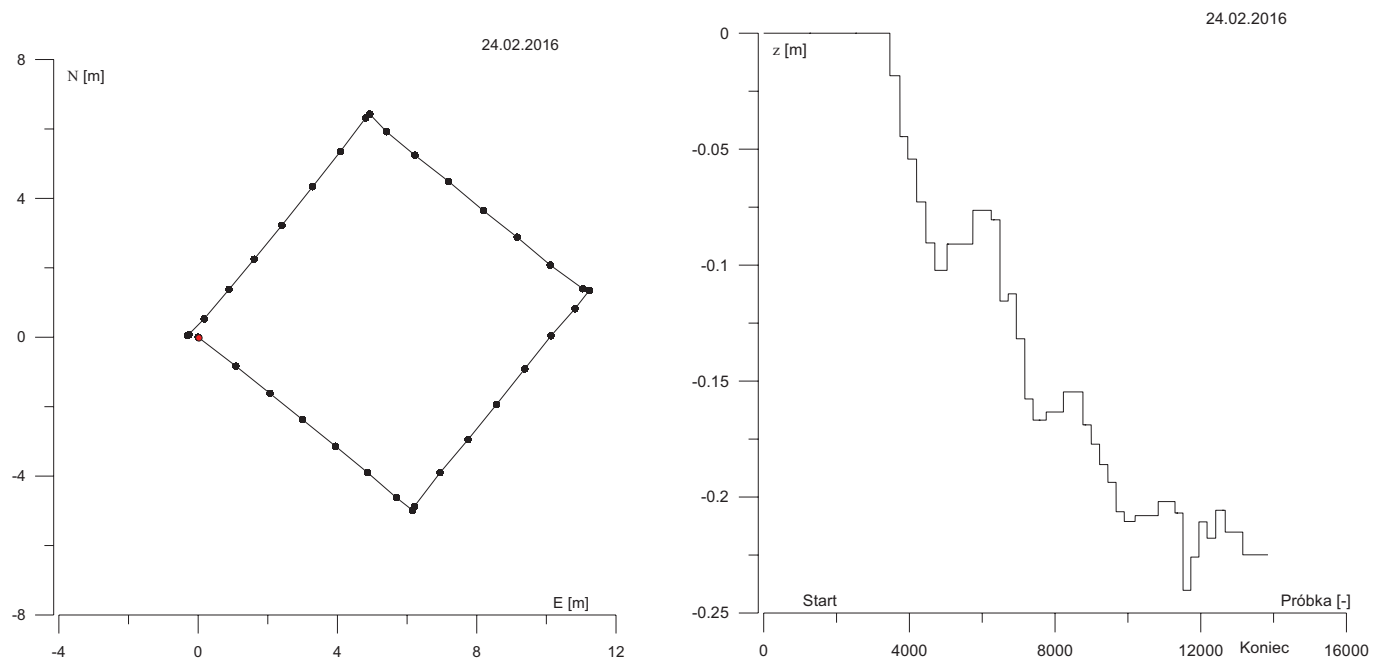

Fig. 19. Measured trajectory in the navigation system (left) and a change of altitude (right). The dots on the trajectory represent places where the ZUPT condition is fulfilled, in other words detected steps [Popowski, Dąbrowski, 2016]

Fig. 20 (left) shows measured lengths of individual steps L in the course of the route as a function of the number of recorded samples, demonstrating that each $8 \mathrm{~m}$ side of the square was achieved in six double steps of approximately $1.2 \mathrm{~m}$ in length. and one single with a length of about $0.6 \mathrm{~m}$.

Figures 19 (left) and 20 (right) show trajectories of movement in a square track. In the first case, the route was led all the way forward, with 90 degrees turns in the corners of the square. In the latter case, the whole route was accomplished without changing the course. First, the march forward, then sideways movement to the left, next a side of the square walked backwards, and the last section moving sideways to the right. During the whole exercise the course has not changed. 

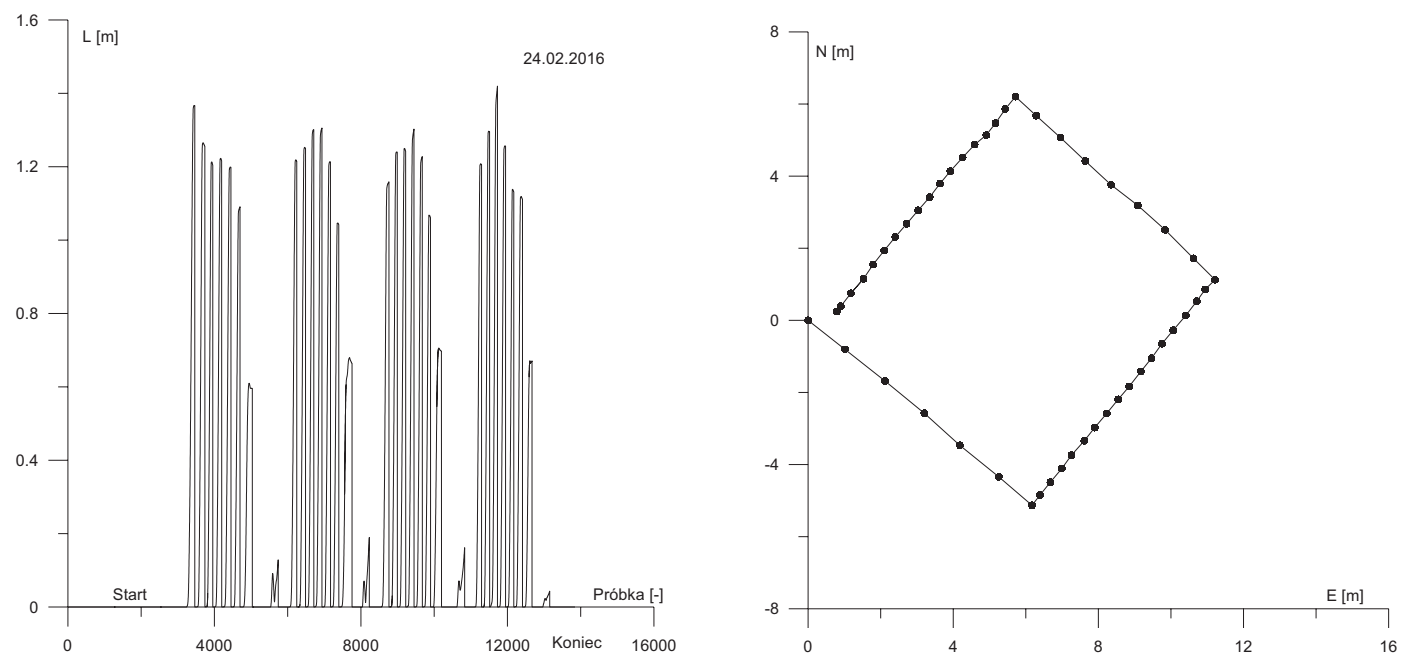

Fig. 20. Measured lengths of individual steps (left) and the trajectory in the navigation system while walking with no change of yaw angle (right) [Popowski, Dąbrowski, 2016]

In both cases of the path, the trajectory was the same. In case of using deadlock navigation, where the step length would be estimated (for example from vertical acceleration values), the components of this length in east and north directions would be calculated using the course system, in the latter case, the final point would be $32 \mathrm{~m}$ from the starting point on the straight line lying on the first side of the square. As a result, a very large error of $32 \mathrm{~m}$ would occur.
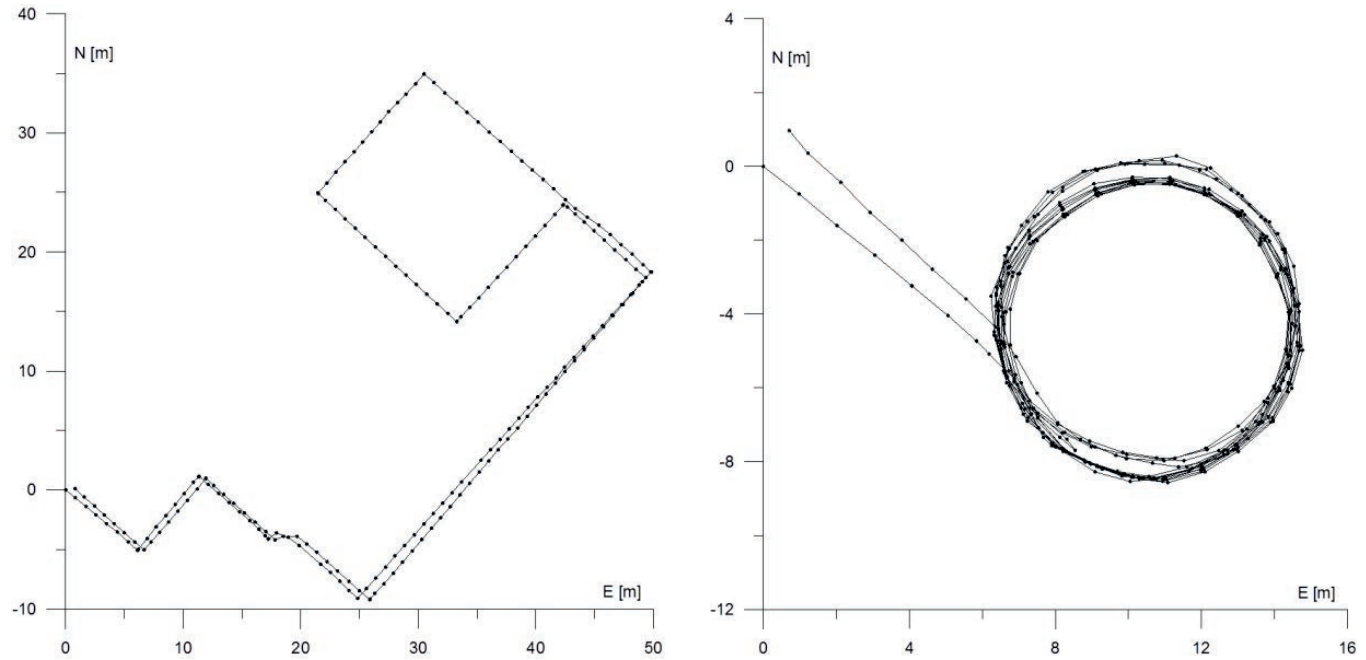

Fig. 21Trajectories during walking the track: (left) at route points from Fig. 9 with a length of $230 \mathrm{~m}$ in $300 \mathrm{~s}$ and on an $8 \mathrm{~m}$ diameter circle for a length of $400 \mathrm{~m}$ in $600 \mathrm{~s}$ (right) [Popowski, Dąbrowski, 2016] 
The presented experiment shows that in the examined system the road measurement was performed by double integration of acceleration components in the navigation system. This solution ensures that the correct trajectory is measured irrespectively of its movement, i.e. it can be moved forward, sideways or backwards. The only condition is that during shoe contact with the ground the ZUPT procedure must be performed.

The above experiment illustrates the differences between inertial navigation with the ZUPT procedure and typical deadlock navigation with an estimated step length and course measurement. For navigation in buildings - especially in tight spaces - only inertial navigation with the SOPT procedure guarantees correct position measurement.

Figure 21 (right) shows the trajectory of movement when walking on a circle track of about $8 \mathrm{~m}$ in diameter. The march started at a point with coordinates $(0,0)$ and included 10 full turns counterclockwise and then 5 turns clockwise. The exercise was ended at the starting point. The entire passage, including a short stop, took about $600 \mathrm{~s}$ (10 min), and the distance travelled was about $400 \mathrm{~m}$.
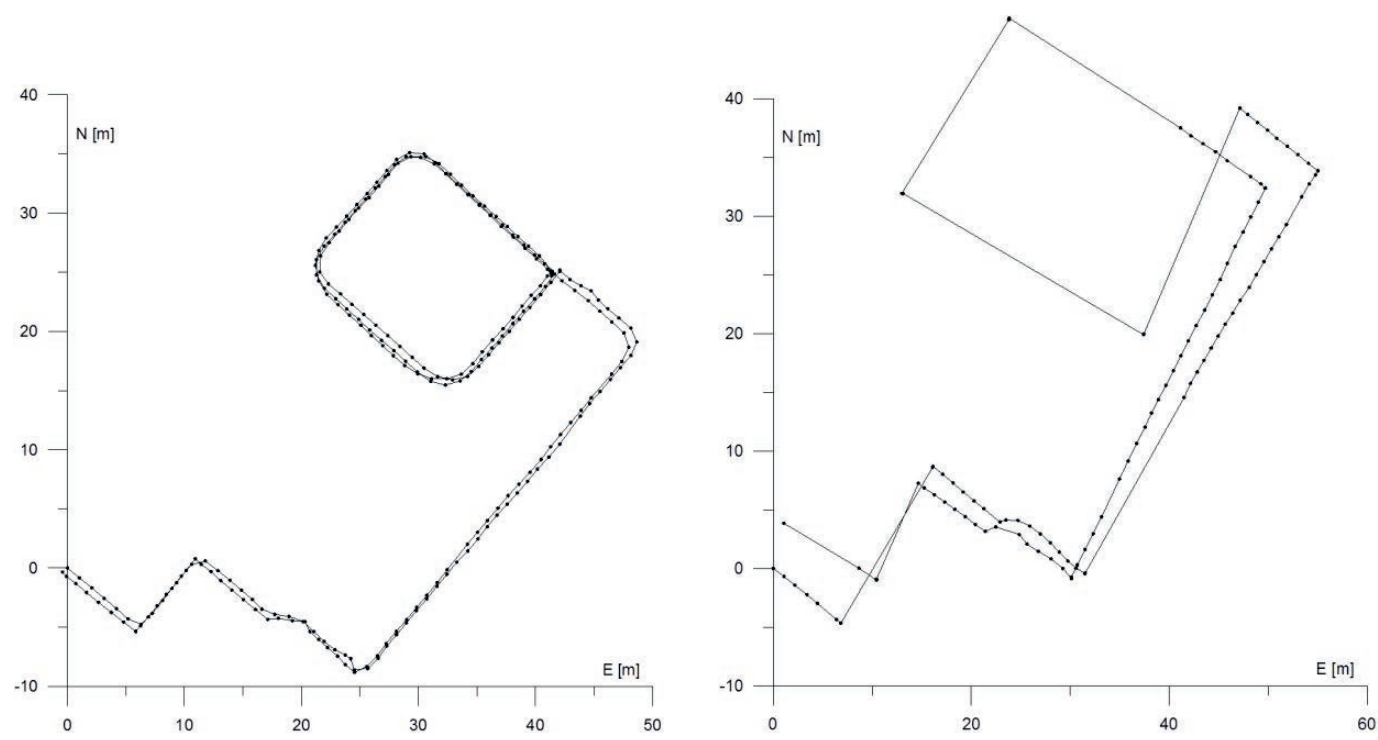

Fig. 22. Left: $360 \mathrm{~m}$ route in $6 \mathrm{~min}$, Right: $230 \mathrm{~m}$ route with frequent failures to meet the ZUPT criteria [Popowski, Dąbrowski, 2016]

A route of about $230 \mathrm{~m}$ was prepared for testing the system. This route can be extended by multiplying the loop at its end.

Fig. 21 (left) shows the routes along the track of $230 \mathrm{~m}$ walked in 5 minutes. Figure 22 (left) shows $350 \mathrm{~m}$ track completed in 6 minutes. Figure 22 (right) illustrates the situation when the conditions of the ZUPT procedure are not met during the walk. The integration process does not stop there, and long sections of the route appear where integration takes place continuously, without interruption. As you can see this effect has increased the size of errors. 


\subsection{Vertical channel of the navigation system}

Fig. 23 shows the static pressure (ps) and position (altitude) graphs when climbing the stairs to the upper floor and then returning to the original level.
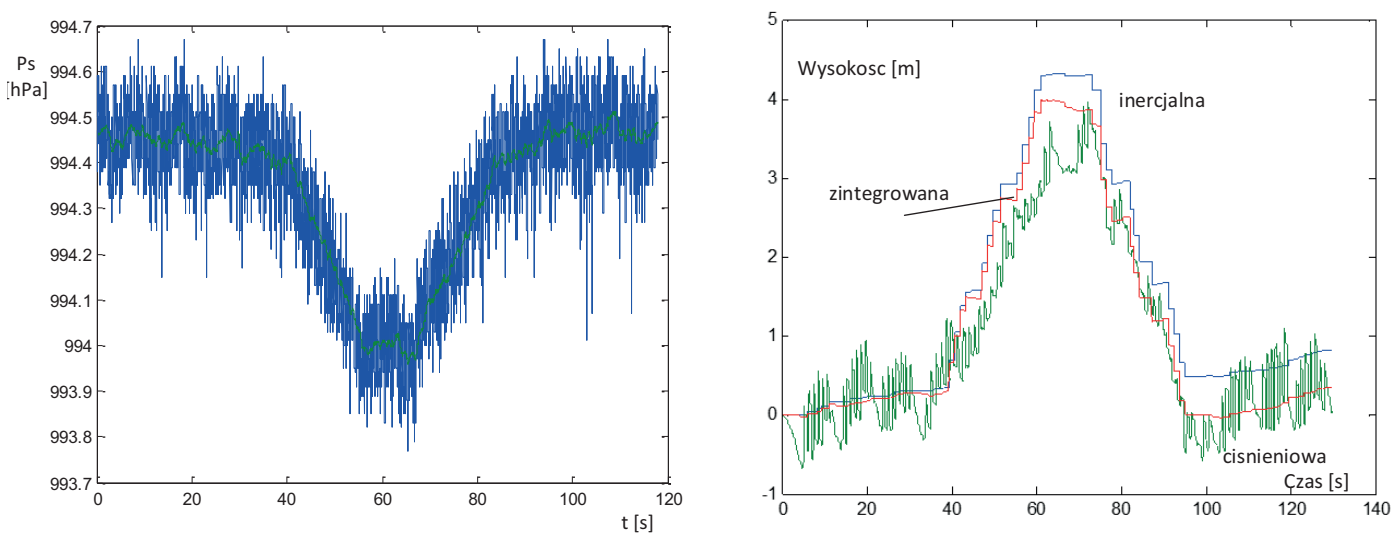

Fig. 23. Static pressure graph when climbing and descending stairs (left), altitudes: barometric, inertial and integrated (right) [Popowski, Dąbrowski, 2016]

The vertical (inertial) altitude graph clearly shows a change of altitude of about $0.7 \mathrm{~m}$ within $130 \mathrm{~s}$ of navigation. The registered altitude change between the floors was $3.9 \mathrm{~m}$. The barometric pressure sensor recorded a pressure change of approximately $0.5 \mathrm{hPa}$. Figure 23 (right) shows the results of the altitude measurement. Inertial altitude, barometric altitude [14] and integrated altitude. The integration was made by means of complementary filtration.

\subsection{Estimation of IANS accuracy}

The accuracy of ISAN system has been estimated for tracks $230 \mathrm{~m}$ long. A total of 10 passes were made over a two month period. The first four transitions were executed without interfering with gyroscope drift in the $\mathrm{z}$ axis. Based on these results, an average drift was calculated which minimized navigation errors. This average drift was then introduced into the channel "from" the gyroscope and subsequent attempts were made. It turned out that navigation errors significantly decreased (Figure 24).

Errors obtained in consecutive samples reached about $1 \%$ and less. This phenomenon can be attributed to previously unadjusted constant gyroscope drift in the $\mathrm{z}$ axis. It can also be a stable, slow-moving accidental drift that could be effectively compensated in a short period of time.

Basing on conducted tests, the declared accuracy of the system was determined in a fully autonomous mode for $1 \%$ of the journey, provided that it is a typical medium speed march with no stops. 
IANS error estimation [\%]

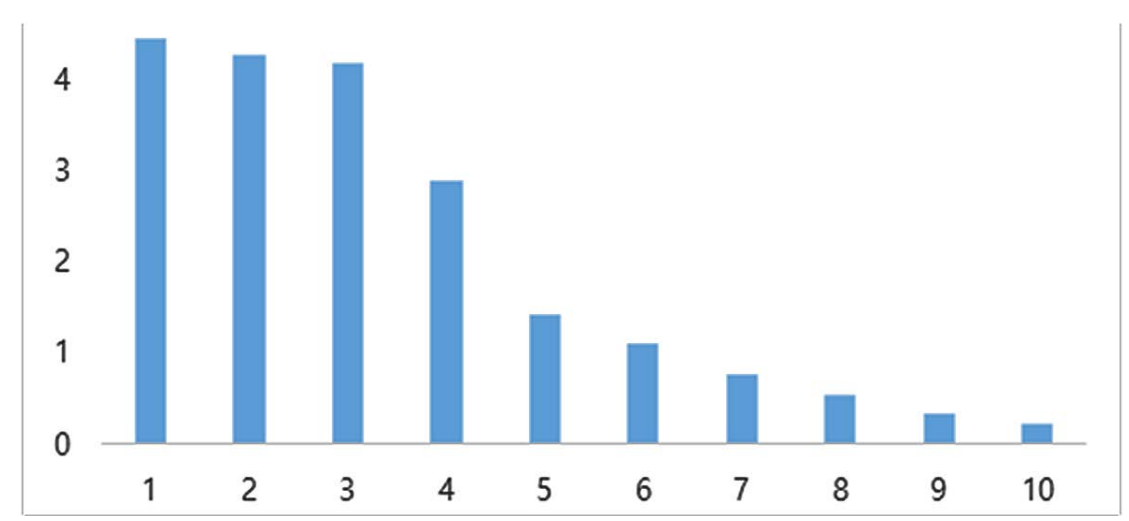

Fig. 24. Error values ( $\%$ of distance travelled) for ten samples for IANS navigation system [Popowski, Dąbrowski, 2016]

\section{CONCLUSIONS}

1. Individual deadlock navigation systems based on inertial measurements can be divided into two groups. The first, which uses the Schuler system (for a longer measurement time, more than 20 minutes) and the second one, using the ZUPT procedure. Both these solutions limit the navigation errors. The Schuler layout is more universal and can be used on any object, but the accuracy requirements of the sensors are very high. The gyroscopes must accurately measure the spin speed of the Earth. Currently in individual navigation systems this method is practically not used. However, the ZUPT procedure is widely used today. The process of walking naturally is predisposed to its application. Each step consists of the phase of contact with the ground and the phase of motion. Navigation is conducted in the second phase, and in the first one the ZUPT procedure can be carried out. With this procedure you can specify the orientation angles and the length of the step. Due to the method of measuring the step length, you can distinguish at least three groups of navigation systems. The most recommended, because of the reliability of the results, is to count the paths directly from the measured accelerations with compensation of gravitational accelerations and curvilinear motion and zeroing the linear velocity at each step when the shoe is in contact with the ground. The effect of such a system is shown in Figure 19 (left) and 20 (right) for the movement on a square track. Please note that in this case the sensors must be in the shoe. Attempts to transfer sensors to another location are a major problem in the implementation of the ZUPT procedure. In the work [12] and [13], an attempt was made for the case of land navigation in an attempt to introduce the ZUPT procedure in static and dynamic conditions. You can also estimate step length from intermediate acceleration values. In the paper [15], four methods of solving this problem using vertical measurements were presented. In the simplest systems, the length of a step can 
be estimated in an elementary manner, either by making its length dependent on its duration, or assuming that the number of steps per minute divided by the length of the step in meters is constant and is for example 140 (so-called cadence).

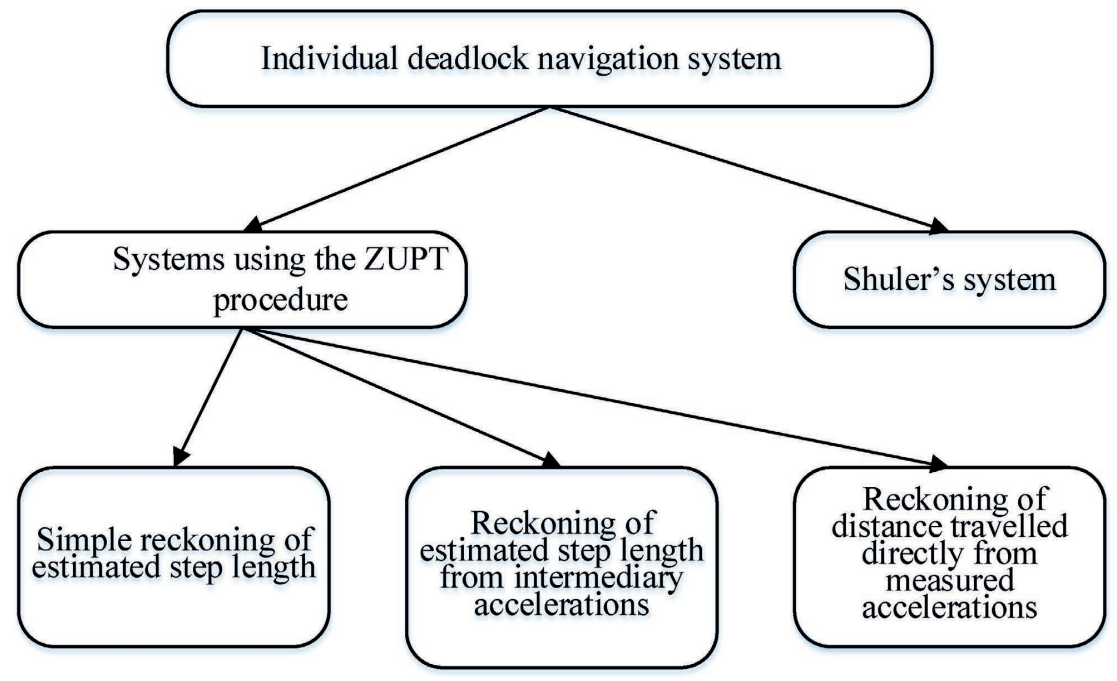

Fig. 25. Possible configurations of Individual Automatic Navigation System [Popowski, Dąbrowski, 2016]

2. The pre-tested models of the navigation system led us to conclusion that the basic functions of the system had been fulfilled. These functions include:
a. measuring current angles of orientation,
b. calculating the length of each step,
c. calculating velocity components in the object related system (shoe) and in a navigation system,
d. calculating current geographical coordinates of local system,
e. transmitting measured data by CAN line.

3. It was confirmed that navigation accuracy is less than $1 \%$ of the travelled distance. This accuracy was achieved after introducing the average drift of the gyroscope in the $\mathrm{z}$ axis of the last four passes. In the absence of this compensation, the accuracy of approximately $4 \%$ of the distance travelled has been obtained.

4. In the vertical channel, the inertial altitude correction was proposed using a barometric altimeter. Thus the assumed accuracy of 0,5 m was achieved with long term stability.

5. The target solution is to place the sensors together with a converter in the shoe heel. This will eliminate the interference-sensitive beam. All elements of the system should constitute one unassembled monolithic assembly in a form of a shoe sole.

6. The wire bundle coming out of the shoe should be completely sewn into its construction. It is unacceptable to leave fragments of bundle sticking out of the shoe, which may lead to easy and quick damage. 


\section{BIBLIOGRAPHY}

[1] Merhav S., 1996, “Aerospace Sensor Systems and Applications”, Springer -Verlag, Chap. 5.

[2] Popowski S., 2011, „Ograniczanie błędów w nawigacji inercjalnej”. Prace Instytutu Lotnictwa, 221, Warszawa, str. 161-172.

[3] Feliz R., Zalama E., García-Bermejo J., 2009, "Pedestrian tracking using inertial sensors", Journal of Physical Agents, 3(1), pp. 35-42.

[4] Rahim K. A., 2012, "Heading drift mitigation for low-cost inertial pedestrian navigation", $\mathrm{Ph}$. D. thesis, University of Nottingham, UK.

[5] Yun Cho S., 2006, "MEMS Based Pedestrian Navigation System", The Journal Of Navigation, 59, pp. 135-153.

[6] Jimenez A. R., Seco F., Prieto J.C. and Guevara J., 2010, “Indoor Pedestrian Navigation using an INS/EKF framework for Yaw Drift Reduction and a foot-mounted IMU”, 7th Workshop on Positioning, Navigation and Communication.

[7] Godha S., Lachapelle G., Cannon M. E., 2006, "Integrated GPS/INS System for Pedestrian Navigation in a Signal Degraded Environment”, ION GNSS 2006.

[8] Alvarez J. C., Alvarez D., López A., Rafael C. González R. C. 2012, "Pedestrian Navigation Based on a Waist-Worn Inertial Sensor”, Sensors (Basel), 12, pp. 10536-10549.

[9] Grejner-Brzezinska D.A., Toth C. K., Moafipoor S., Hyoun Kwon J., 2017, “Design and calibration of a neural network-based adaptive knowledge system for multi-sensor personal navigation”, from: http://www.isprs.org/proceedings/XXXVI/5-C55/papers/dorota brzezinska.pdf.

[10] Nilsson J. O., Skog I., Handel P., 2012, "A note on the limitations of ZUPTs and the implications on sensor error modeling”, 2012 International Conference on Indoor Positioning and Indoor Navigation.

[11] Szymanowski J., Grzelak J., Popowski S., 2003, "Static Initial Azimuth Update Method in Land Navigation Systems", Annual of Navigation, 6.

[12] Szymanowski J., Grzelak J., Popowski S., 2004, "Dynamic Initial Settings Update Method in Inertial Navigation Systems", Annual of Navigation, 8.

[13] Popowski S., 2011, „Weryfikacja koncepcji pomiaru wysokości i prędkości pionowej lotu wybranych obiektów latających", Prace Instytutu Lotnictwa, 221, str. 143-160.

[14] Jahn J., Seitz J., Patino-Studencka L., Batzer U., Boronat J. G, 2010, "Comparison and Evaluation of Acceleration Based Step Length Estimators for Handheld Devices", 2010 International Conference on Indoor Positioning and Indoor Navigation, Zurich.

[15] Szpakowska-Peas E., Grabowski T., 2016, „Dokumentacja Modułu ISAN Wersja MINI”, sygnatura CTKA/DT/2016/004, materiały wewnętrzne CTKA Instytutu Lotnictwa.

[16] Szpakowska-Peas E., Grabowski T., 2016, „Dokumentacja Modułu ISAN Wersja MIKRO”, sygnatura CTKA/DT/2016/005, materiały wewnętrzne CTKA Instytutu Lotnictwa. 


\section{INDYWIDUALNY SYSTEM AUTONOMICZNEJ NAWIGACJI}

\section{Streszczenie}

W artykule zaprezentowano Indywidualny System Autonomicznej Nawigacji (ISAN) wspierający działania ratownika lub strażaka w zakresie nawigacji. Przedstawiono podstawowe założenia, które musi spełniać taki system w zakresie funkcjonalności i dokładności. Koncepcję systemu ISAN oparto na wykorzystaniu nawigacji inercjalnej, która jako jedyna pozwala na w pełni autonomiczną pracę. Czujniki pomiarowe systemu nawigacji, wraz z pakietem przeliczającym, umieszczono w bucie ratownika. Aby ograniczyć narastanie błędów nawigacji, co w przypadku nawigacji inercjalnej ma charakter wykładniczy, wprowadzono do proponowanego systemu procedurę uaktualniania parametrów nawigacyjnych w każdym kroku ratownika. Pozwoliło to na osiągnięcie wymaganej dokładności prowadzenia nawigacji. W artykule opisano opracowany i wykonany demonstrator technologii oraz przedstawiono podstawowe wyniki jego badań. Badania przeprowadzono w budynku podczas kontrolnych przejść płaskich o długości rzędu kilkuset metrów, w czasie do 10 minut. Wykonano również badania przejść ze zmianą wysokości, w celu oszacowania dokładności w kanale pionowym. Wyniki tych badań demonstratora pozwalają na stwierdzenie, że dokładność tak prowadzonej nawigacji jest rzędu 1\% przebytej drogi i ma charakter liniowy względem czasu. Uzyskane dokładności są w pełni wystarczające do zastosowania praktycznego ISAN.

Keywords: rescuer navigation system, inertial navigation system, ZUPT procedure, Individual Autonomous Navigation System, IANS.

The work presented in this article has been financed from NCBiR funds under the contract nr DOBR/0038/R/ID2/2013/03. 